\title{
LOS EFECTOS DE LOS AFECTOS EN LA MOTIVACIÓN Y LA AUTORREGULACIÓN ${ }^{2}$
}

\section{AFFECT IMPACT ON MOTIVATION AND SELF-REGULATION}

\author{
Juan Antonio Huertas \\ Universidad Autónoma de Madrid, España
}

Palabras clave: motivación, autorregulación, emoción, aprendizaje

Keywords: motivation, self-regulation, emotion, learning

Llevo mucho tiempo viniendo a la UCUDAL. Me ha llamado la atención lo que ha dicho el Prof. Trías al presentarme, es verdad, empecé hace mucho tiempo en esta Universidad con los primeros pasos del Postgrado de Psicología de la Educación, cuando las transparencias era en acetato en blanco y negro y ahora estamos a colores. Desde entonces esta institución ha avanzado mucho, en Psicología ha progresado tremendamente, y me encuentro en un Centro muy hermano, muy competente. También les tengo que reconocer que la primera vez que vine aquí en el año 97' - 98' había más distancia entre la Psicología que se hacía aquí y la que se hacía en España, que la que hay ahora. En ese sentido, desde hace ya algunos años las veces que vengo aquí, vengo a compartir más que a enseñar.

Yo lo que tenía pensado hacer hoy es algo que no sé si me va a salir, y es daros información común de dos aspectos que son importantes en la motivación; es decir, ilustraos y daros información y conocimiento que son clásicos en asuntos de motivación, pero también darlo con un determinado guión, con un determinado argumento. $Y$ ese argumento en alguna forma recoge investigaciones últimas. Quiero hacerlo en un formato muy narrativo, es decir, no voy a llenar de citas eruditas lo que voy a contar, os voy a contar un cuento con moraleja. No sé si esto va a funcionar o no, yo espero que si; y en cualquier caso hay una cosa que quiero hacer y espero que me salga bien, es fácil, y es dejar un espacio para las preguntas y para el intercambio.
Básicamente en términos de información, voy a hablar de motivación intrínseca y voy a hablar de autorregulación, que son dos conceptos típicos y claves, que llevan veinte años, por decirlo así, en el candelero a la hora de conocer los asuntos de motivación humana desde la psicología. Pero la novedad es que voy a tratar de hacer una crítica de esos dos conceptos, porque creo que hay otro que está escondido y es más importante y que ahora desde la psicología cognitiva estamos empezando a abordar, que son las emociones y los afectos y que realmente pueden socavar o modificar el orden de prioridades que se habían establecido los teóricos de la motivación intrínseca o la autorregulación.

Cuando uno explica motivación, tiene que decir que la motivación no es algo que esté en el mundo racional, ni es algo que esté en el mundo pasional. Aquellas cosas que gobiernan mis cosas del querer, son procesos racionales y también son procesos emocionales. Un típico proceso racional que gobierna las cosas del querer son los procesos atribucionales, es decir, el por qué hago lo que estoy haciendo; el por qué he sacado el resultado académico que he sacado, que es una explicación que yo me doy y para la cual puedo hacer un análisis muy racional. Está claro que la explicación que me doy determina la motivación que yo voy a tener en el futuro. Es decir, está claro que como yo me explique mis éxitos y mis fracasos va a determinar mi desempeño en esa misma tarea. $Y$ ese sería el componente racional. Pero también es evidente que hay cosas que quiero, me gustan 
y ese querer o gustar no está supeditado a un análisis racional, a un análisis beneficio-costo, un análisis de "yo quiero estudiar el master de no se qué porque me va a posibilitar a y c". Hay siempre un componente de ese yo quiero estudiar el master que está determinado simplemente porque me gusta, porque ese tema me interesa, porque me llama la atención y me atrae. "Pero te va a costar mucho, vas a tener que dejar parte del trabajo, vas a tener que trabajar los sábados por la mañana", bueno y qué? Me gusta. Hay claramente un componente emocional en todo acto de querer. Evidentemente el término querer en castellano significa emociones. Pero la psicología, la psicología cognitiva, la psicología más empírica no ha sabido trabajar con los afectos. La psicología dinámica por el contrario, sólo ha sabido trabajar con los afectos. El caso es que desde la psicología cognitiva, como desde las neurociencias, a partir de los años 90' hay una revolución para estudiar las emociones. Seguramente os suena Antonio Damasio o LeDoux que empiezan a estudiar los grandes centros de control emocional. La psicología cognitiva ha dado el paso desde los modelos fríos a los sistemas calientes y ha dejado los esquemas fríos. En la psicología de la motivación y en la psicología de la conciencia, de la autorregulación, eso está pasando también: empiezan a incorporarse con posibilidades de estudio más o menos sistemáticos, utilizando la metodología que se utiliza en la psicología cognitiva, los afectos.

Vamos a hablar de los efectos de los afectos en la motivación intrínseca y en la autorregulación. Vamos a empezar por la motivación intrínseca. El término de motivación intrínseca como sabéis es un término más o menos famoso, que empieza a mediados del siglo XX y que significa "hacer lo que me da la gana". No hace falta buscar una definición mucho más elaborada, es sencillo uno está motivado intrínsecamente cuando hace lo que le da gana. Los españoles -que son monárquicosdicen "lo que me da la real gana", pero aquí la gana es republicana. Los autores principales en esta corriente son Edward Deci y R. Ryan. Richard Ryan es quizás ahora el más señero, que está trabajando con esto en una onda cada vez más cercana a este movimiento discutible de la psicología positiva. Qué dice Ryan sobre qué sostiene la motivación intrínseca? Ryan dice que el hacer lo que me da la gana está sustentado en tres grandes elementos y el primero es el más importante. El primero es lo que él llama la autodeterminación o autonomía. El tema de la autodeterminación en español tiene un significado distinto que en inglés, por eso algunas veces usamos mejor autonomía. De hecho Ryan no habla de la teoría de la motivación intrínseca, Ryan habla de la teoría de la autodeterminación. Ryan considera que la autodeterminación es una necesidad de todo ser humano. El ser humano tiene una necesidad de comer, tiene una necesidad de beber, tiene una necesidad de reproducirse y hay algo que también tiene necesidad y es ser uno mismo. Es decir, tener el control sobre su vida. No es una necesidad de déficit como el comer o el beber, que uno lo nota cuando baja la glucosa en sangre o cuando se dispara la sed porque baja el nivel de hidratación. La autodeterminación es algo que está siempre presente. Para Ryan la autodeterminación es la necesidad de hacer las cosas por mi mismo, porque lo he decidido yo, porque controlo yo. Debajo del concepto de autodeterminación hay otros conceptos que quizá habéis visto en psicología educacional, que es la sensación de control (locus of control) o la sensación de causalidad: controlar y ser la causa, no ser una marioneta. Dice Ryan que, cuando yo consigo hacer algo por mi propio interés intrínseco, eso tiene una carga motivacional tan grande que incluso puedo hacer cosas por ese interés intrínseco aunque el beneficio sea menor que los costos que me genera. O sea, yo puedo hacer un master por el interés de hacer un master, porque me gusta ese master, porque lo he decidido, porque he tomado esa determinación, porque creo que es lo oportuno en mi vida, aunque luego al final el rendimiento por haber hecho ese master no sea satisfactorio, pues no he cambiado de empleo, no ha cambiado mucho mi vida, solo ha cambiado simplemente el conocimiento que yo tengo y he aprendido. Incluso es más, dice Ryan que las personas que tienen más sensación de autodeterminación son más felices. La clave de la felicidad humana entonces, es poder tomar decisiones por uno mismo, poder hacer las cosas que yo quiero, y saber manejarme por ellas. Es decir, no ser marioneta, ¿se entiende? Es la idea filosófica del libre albedrío y es el fundamento básico de la motivación intrínseca. También los autores de autodeterminación dicen que los niveles de autonomía, los niveles de autodeterminación no deben ser escasos, 
porque entonces nos sentimos marionetas, pero tampoco pueden ser absolutos porque generan incertidumbre. Es decir, para yo estar motivado intrínsecamente, tengo que tener unos niveles de autonomía intermedios. Os pongo un par de ejemplos: un estudiante no estará interesado por una materia si lo que tiene que hacer en esa materia es todo lo que le impone el profesor, al capricho del profesor a su dictado, entonces se sentirá una marioneta: "no me dejan hacer cosas sino yo tengo que hacer lo que me mandan". Ese es un sistema de poca autonomía; pero lo que dice la teoría y es cierto, es que si tú pasas al polo contrario, es decir, si tú al estudiante le dices "haz lo que te de la gana, cualquier cosa sirve para aprobar la materia. Entonces qué debo hacer profe? Puedes tirar por aquí, puedes tirar por allá, con tal de que tú aprendas yo te voy a aprobar". El estudiante no está nada orientado, nada guiado y esto le genera la misma incertidumbre que antes. Es más, cuando nos colocamos en esa situación, nuestro remedio es copiar al otro. Es decir, nos convertimos en marionetas. "Tú qué has entendido que debemos hacer? Yo nada. Entonces qué vamos a hacer? No sé, fijémonos qué hace este". Y entonces hacemos lo que hace ese. Para Ryan esto es lo fundamental de la motivación intrínseca.

Luego habla de otros dos factores que son relevantes y están supeditados a la autodeterminación. El siguiente es lo que yo creo que se: mi sensación de competencia. Las creencias que tengo sobre cuáles son mis habilidades, mis dominios, mis conocimientos. La idea de que si yo quiero estar motivado intrínsecamente tengo que saber qué es lo que sé, y buscar saber más. De manera que los escenarios que más ayudan a la motivación intrínseca son aquellos que me generan un cierto desafío. Es decir, que yo me puedo situar en ese escenario en un papel de competencia y ese escenario me proporciona la posibilidad de ir aprendiendo un poquito más. En el fondo, esta es otra forma de describir algo que probablemente habéis visto en vuestras asignaturas, que es la idea vygotskiana del área de desarrollo próximo, el reto óptimo o el desafío. Y es algo que podemos encontrar cuando analizamos los retos motivacionales de algunos videojuegos. Ahora voy a irme con otro ejemplo completamente distinto al académico. Hay un videojuego que es buenísimo, que tiene treinta años ya y todavía se sigue jugando, aunque ninguno de vosotros que estáis en una formación académica superior y de posgrado habéis jugado nunca, evidentemente, que es el Tetris. Nunca habéis jugado al tetris, vosotros tenéis un nivel..., lo conocéis porque os lo han comentado, bueno a lo mejor lo habéis visto y a lo mejor alguien se ha quedado enganchado con el Tetris. El Tetris proporciona sensación de competencia, no hace falta tener muchos conocimientos para saber cuáles son las reglas del Tetris, incluso vosotros sabéis cuáles son las reglas, no habiendo jugado. Por lo tanto es fácil que el primer nivel te salga bien, si te sale mal es por tu culpa, genera autodeterminación. Bueno, es verdad que siempre podemos achacar el fallo a alguien que te empuja o que te habla o te distrae, pero vamos, por lo general nuestros resultados en el juego se deben a nosotros mismos. $Y$ conforme vais realizando bien la tarea, el siguiente nivel es un poquito más complejo, y el siguiente nivel es un poquito más, y el siguiente más, y al final uno acaba fallando siempre. Pero, está tan bien graduada la sensación de competencia con el nivel de dificultad que, cuando uno falla vuelve inmediatamente a la casilla de salida y lo vuelve a intentar. Ese sería un ejemplo del papel de la autodeterminación y de la sensación de competencia.

Esto en los términos educativos, lo que nos viene a decir es que, en la medida que nosotros coloquemos la dificultad de la tarea que tienen que hacer nuestros estudiantes un poquito por delante de su sensación de competencia, conseguiremos estudiantes que puedan quedarse absortos con la tarea, que la tarea les resulte interesante porque les significa el avance justo que necesitan.

Hay otro aspecto que Ryan no mete muy por el medio pero viene del origen histórico del término de motivación intrínseca, es la curiosidad humana. La curiosidad según esta teoría y muchas otras es algo consustancial al ser humano por el hecho de que nacemos "medio crudos". Perdonadme la expresión pero el ser humano cuando nace es una "mierdecilla", nos dejan en la sabana que es para lo que hemos nacido y nos comen las cebras, no los leones. Nuestra potencia como especie biológica, no es nuestro cuerpo sino es la estructura social en la que nos metemos 
y nuestra capacidad de aprendizaje. Entonces ¿cuál es el ingrediente que hace que una persona quiera aprender?: la curiosidad. Lo digo de otra manera, si no fuésemos personas curiosas no aprenderíamos. Y si no aprendemos no somos biológicamente viables. Entonces ¿qué es lo que nos provoca curiosidad? Lo que nos provoca curiosidad es aquello que nos permite conocer y explorar cosas moderadamente novedosas para nosotros. Lo conocido ya, aburre. Y lo absolutamente desconocido, genera miedo e incertidumbre. El fenómeno de la curiosidad que yo creo que sí lo podemos considerar como natural en todos los seres humanos, quizá también en los chimpancés y hay trabajos de etólogos que lo demuestran precisamente porque estas especies son los siguientes que tienen que aprender mucho para ser viables. Ese fenómeno se mueve exactamente igual en estos niveles medios de autonomía y de sensación de competencia. Este sería el otro componente clásico de la motivación intrínseca.

En las primeras teorías sobre desarrollo teórico de Deci y Ryan no había un tercer componente. La siguiente dimensión nosotros la hemos traducido al español como apoyo social, Relatioship, es decir, tener relaciones: apoyo mutuo. Lo que viene a decir Ryan es que cuando uno está motivado intrínsecamente y esta autodeterminado lo tiene que hacer en un determinado entorno. $Y$ tiene que ser un entorno relajado, un entorno seguro, un entorno de confianza. Los entornos relajados, seguros y con confianza son los entornos en los que disponemos de un apoyo social. Para estar interesado se tiene que estar en un determinado clima emocional que sea por decirlo así, positivo. Cuando nosotros hacemos algo porque nos da la gana, necesitamos ese entorno. Imaginaos que tenéis un tiempo libre un sábado por la mañana, no sé si realmente esto ocurre, entonces estáis estudiando algo, os buscáis un entorno bueno, Cuando os matriculáis en un master porque queréis aprender más, continuáis si realmente el clima es bueno. $Y$ algunas veces el clima sustenta los dolores de aprender. "La asignatura es costosa, esta materia me está resultando dura pero el ambiente es muy bueno, mis compañeros me ayudan, el profesor también es cercano y así sí se puede". Pero para Ryan este último componente es simplemente el decorado, el marco de referencia, lo importante es la autodeterminación. De manera que a partir de las teorías de Ryan y con este movimiento de la psicología positiva, lo que se ha hecho en toda la intervención motivacional: primar el papel de la autonomía, el papel de la autodeterminación. Ahora vamos a discutir esto y para ello os voy a poner un ejemplo de lo que se entiende como útil para la intervención motivacional en el aula.

No os voy a contar, porque no es el objeto de esta charla, cómo motivar en el aula, pero os voy a decir un aspecto clave para la motivación en el aula y es cómo tenemos que diseñar las actividades académicas para que éstas sean motivantes. Siguiendo esta teoría, la clave es diseñar las tareas académicas de manera que generen grados de libertad, que generen autonomía en el aprendiz. Entonces se dice que, conviene generar distintas alternativas para conseguir aprender un contenido, una competencia, un conocimiento, de manera que el estudiante tenga la sensación de que elige, como en el Tetris. La sensación de que elige, aunque realmente no elige. En el Tetris todos tenemos la sensación de que colocamos la pieza en el lugar que corresponde porque la podemos mover como nos gusta. Realmente la pieza se puede mover solo en dos dimensiones, no se puede mover en la tercera, si la pudiésemos poner de canto siempre encajaría, pero seguimos teniendo la sensación de que somos nosotros los que movemos la pieza. De la misma forma, un educador puede generar distintas alternativas de trabajo para que el estudiante tenga la sensación de que está eligiendo la que más le conviene, pero el educador sabe que cualquier alternativa de trabajo le va a llevar el mismo aprendizaje y que además son tres, no son cuatro las posibilidades, la cuarta no vale.

Evidentemente la siguiente clave para diseñar tareas motivantes es fomentar la toma de decisiones, no solamente la elección, el uso de las herramientas a partir de generar grados de libertad en el aprendiz, lo que se llama el aprendizaje autónomo famoso, que ahora hay en muchos diseños curriculares de la universidad incluso. Derivado de lo que hemos visto antes: generar tareas que provoquen desafíos, moderadamente difíciles para que creen un reto, lo que hemos visto hace poco. 
Esto sería, por decirlo así, lo canónico, el canon establecido para cómo diseñar tareas a partir de la teoría de la autodeterminación, para que el estudiante se sienta motivado para aprender.

Llevamos muchos años, incluso incluyo mi trabajo en ellos, dando cursos de formación a docentes para que hagan estas cosas; haciendo proyectos de investigación para que los estudiantes aprendan mejor, y tendiendo resultados relativamente buenos, cuando el estudio lo hacemos en condiciones de laboratorio muy controladas. Los resultados son mucho más pobres cuando lo hacemos en condiciones naturales, con grupos de estudiantes de verdad y con una condición curricular establecida. Se obtiene además un resultado curioso y es que esto funciona bien con los mejores estudiantes, que es un resultado también predecible. Es decir, aquel que ya está motivado intrínsecamente, que quiere aprender, te pide esto. Pero claro, yo no hago una intervención educativa únicamente para los mejores, al revés yo quiero hacer una intervención psicoeducativa con aquellos que necesiten, que tienen problemas. ¿Y qué pasa con ellos? Si yo hago un estudio empírico y mezclo a los estudiantes, los buenos, los malos y los regulares en esa asignatura y mido el efecto de ésto, como el efecto es muy bueno en los buenos, el resultado de las medias y las desviaciones típicas y los contrastes de hipótesis que yo haga me va a salir bien, me va a salir que he producido efectos positivos. ¿Qué pasa si yo organizo a los estudiantes en virtud de niveles de rendimiento? Pues las investigaciones que hacen eso demuestran lo que os acabo de decir: que funciona con los buenos y no funciona con los malos. En cualquier caso. ¿Qué pasa si yo le pregunto a los estudiantes qué opinión tienen de los experimentos que yo he hecho con ellos? Después de haber hecho una intervención psicoeducativa, le pregunto a los estudiantes ¿y cómo valoras lo que yo he hecho?; ¿qué cosas te parecen adecuadas y qué cosas no te parecen adecuadas?.

En los últimos diez años han aparecido investigaciones que van con este enfoque. Visto que esto es difícil llevarlo a la práctica real, veamos por qué falla. Como víctimas del experimento qué cosas veis positivas o no. Os voy a contar los resultados de lo que ahí sale. ¿Qué prefieren los estudiantes que están motivados, los estudiantes que quieren aprender? ¿Qué prefieren de todas las cosas que les hemos propuesto y que -en teoría- todas ellas son acciones positivas para que quieran aprender? Te dicen que cualquier aspecto que tenga que ver con estimular la curiosidad, con generar la novedad, esas estrategias -incluso las comunicativas- les parecen oportunas. Te dicen que más que darles metas de autodeterminación, les enseñes la relevancia y la utilidad de lo que está haciendo. Es decir, más que contarles que lo están haciendo por sí mismos, es que les digas el para qué: "tú tienes que aprender esto para poder hacer alguna cosa". Es decir, uno de los grandes problemas que tienen los profesores de psicología, sobre todo en las facultades españolas -donde hay mucho análisis de datos-, es motivar a los estudiantes para que quieran aprender análisis de datos, porque es estadística difícil. La mejor solución es hacerles ver que, eso que están aprendiendo es útil para su carrera profesional y no solamente para hacer investigaciones. Quien consigue hacer esto, tiene estudiantes mucho más orientados para aprender la covarianza, la amplitud semi inter-cuartil y las formulitas matemáticas estas.

Un aspecto muy pequeñito de la docencia, que la mayoría de los autores de motivación no le dan mucha importancia y que es, desde mi punto de vista, tremendamente relevante, además es algo relativamente fácil de hacer y que tiene unos efectos muy grandes, es saber usar imágenes y ejemplos. Anclar en la vida corriente los conceptos teóricos que yo estoy dando. Aquel profesor que es capaz de usar bien las metáforas, es claramente un buen profesor. Esto contradice el canon establecido tradicionalmente de, qué es enseñar una ciencia. Enseñar una ciencia desde la abstracción de sus significados. Pues los estudiantes que más les gusta aprender esas ciencias dicen que los profesores que más aterrizan en el terreno, en el suelo, son los que dan interés y valor a lo que están enseñando.

La cercanía del profesor. Distintos trabajos han demostrado que los profesores que se muestran como un recurso para el aprendizaje, 
no como una autoridad del conocimiento, ayudan a querer aprender. Los profesores que a la hora de comunicar el aprendizaje usan cláusulas del lenguaje en las que demuestran cercanía, es decir, utilizan niveles de lenguaje o géneros del lenguaje próximos al estudiante, que no hablan siempre con esdrújulas, son profesores que ayudan a que aumente el nivel de interés de la materia.

Y en esto de la cercanía hay otro aspecto a destacar, que se ha demostrando, analizando cómo son los buenos profesores en universidades muy prestigiosas. Estudios desde la excelencia docente, viendo a los rubios con ojos azules. Estos buenos docentes, son profesores que tienen todos ellos una característica común, y es que confían en los estudiantes que tienen delante. No los consideran el enemigo; no piensan que el estudiante que está ahí está buscando la manera de zafarse. Yo no sé si hay aquí alguien con un ordenador, una computadora portátil. Si es así yo no estaría pensando si estáis o no chateando por el Messenger, estaría pensando que estáis tomando nota de lo que os interesa. ¿Entendéis la diferencia?, yo soy buen profesor y por eso pienso bien de mis estudiantes.

Hay otro aspecto que define al docente que motiva, que son de los recursos de toda la vida $y$ es que sea un profesor claro y organizado. Al menos que sea el estudiante capaz de predecir lo que va a venir después, es decir, que no le genera incertidumbre, que no sea un desorden vivo. Aunque alguna gente en un primer momento le pueda gustar cierto embarullamiento, porque el desorden puede evocar cierto estilo intelectual interesante, lo divergente, el sujeto que empieza hablando de una cosa y pasa por quince distintas y termina en otra que no correspondía con el tema de la conferencia. Puede resultar atractivo de vez en cuando, pero no ayuda a aprender algo complejo y duradero. El orden, la claridad, la capacidad de poder predecir por parte del estudiante lo que falta y lo que viene, es algo que ayuda a que la gente tenga interés por aprender.

Y luego, la literatura sobre motivación en el aula, enfatiza mucho y con mucha razón que, los sistemas de evaluación que nosotros usamos o que los profesores usan para calificar los conocimientos adquiridos son claves para motivar, y está muy bien dicho. De hecho, otro profesor de motivación -de la Universidad Autónoma que a lo mejor lo conocéis- que es Jesús Alonso Tapia y yo mismo, damos un curso de motivación en el master que se llama: Motivación, autodeterminación y evaluación; porque para nosotros evaluar es motivar. Ha habido muchos diseños de innovación educativa que a lo mejor vosotros conocéis, para mejorar los modos de evaluación de los conocimientos. Que si el portafolio, que si las evaluaciones por objetivos, las rúbricas, etc, etc. ¿Y qué dicen los buenos estudiantes de los cambios en la evaluación? Pues dicen que lo que les gusta es que la evaluación sea clara, justa y equitativa. No son muy positivos con las innovaciones, con los cambios radicales en la evaluación. Consideran que los experimentos se deben hacer con gaseosa. Yo llevo toda una historia educativa siendo evaluado y juzgado de una manera y no quiero muchas variaciones. Además, un buen estudiante, un estudiante motivado, tiene la sensación, aprendida después de muchos años, que una cosa es aprender y otra cosa es la calificación que le pongan. Es decir, un estudiante, todos los que estamos aquí, que tenemos una historia educativa, sabemos que no siempre, o mejor dicho casi nunca, hay una correspondencia directa entre la calificación y los conocimientos, las destrezas y el ánimo que yo tengo, ¿me explico? Consideramos que la calificación y el rendimiento académico son susceptibles a un montón de contingencias que no tienen que ver solamente con el nivel de aprendizaje.

Bueno, ¿qué no quieren estos buenos estudiantes?; ¿qué no quieren estos buenos estudiantes de las innovaciones, que la investigación demuestra que son buenas para ellos?. Lo primero que no quieren es esto último que les estaba diciendo, los experimentos con gaseosa. Los cambios radicales en los modos de evaluación, esta cosa que dice un buen docente y es: "vengo de hacer un master, me han enseñado evaluación del aprendizaje y ahora voy a cambiar la forma de evaluar, ya no lo voy a hacer como yo lo hacía con las otras cohortes". Justo después es lógico que los estudiantes se asusten y maldigan el día en que decidieron o les tocó esta asignatura. 
Una de las cosas que tampoco les gusta a los estudiantes que están muy interesados en un aprendizaje, es demasiado aprendizaje autónomo. Esto yo lo he discutido con algunos de los "popes" anglosajones en motivación (no somos muchos los que trabajamos en esto y nos podemos contactar). A los buenos estudiantes no les importa estar guiados y pautados. Eso no quiere decir que no quieran elegir; o que no necesiten grados de libertad, pero para ellos no es lo único. Tampoco les gusta realizar esfuerzos sin sentido, sin utilidad, sin relevancia. Algunas veces las innovaciones educativas suponen hacer procesos, procedimientos que son largos, lentos y que a lo mejor no tiene tanta rentabilidad. Se prefiere siempre el camino eficaz más rápido y más económico. Y lo que tampoco quieren los estudiantes, que están orientados al aprendizaje, es someterse a muchas innovaciones para hacer cosas muy distintas de las que hace mi compañero de la clase de al lado. Es importante recordar que algunas veces, cuando hacemos innovaciones, generamos grupos especiales y muy marcados, el estudiante no tiene muchas ganas de ser especial, aprender una ciencia no es tan especial, "yo quiero ser uno como otro estudiante cualquiera, ¿a ver si me entiendes?"

¿Y qué pasa con los estudiantes a los que les va mal en una materia?; ¿los estudiantes que les va auténticamente mal, de manera repetida? Estudiantes que ya han conseguido tener miedo al fracaso, que tienen pautas cercanas a la indefensión aprendida, que vienen a decir: "yo no se cómo sacar esta materia por que haga lo que haga es igual, siempre lo hago mal". Estos estudiantes existen y estudiantes que están en esta sala. Estudiantes que somos todos nosotros, que una vez nos ha pasado esto en nuestra historia educativa. No hace falta que levantemos la mano, como si esto fuera una reunión de alcohólicos anónimos y que digan: "lo confieso sí, a mi me paso una vez", porque a todos nos ha pasado. Estos son en principio a los estudiantes a los que dirigimos nuestra intervención motivacional. ¿Qué piensan de esto?; ¿qué es lo que les gusta de la intervención que sufren?. Los datos de aquellas pocas investigaciones que se han molestado en preguntarles son demoledores. Casi nada de lo que se ha hecho con ellos es valorado positivamente. Incluso algunas de las nuevas pautas reciben un valor negativo. Lo consideran incluso peor que lo que había en sus clases antes de la intervención. Esta es -al menos- su percepción subjetiva. Se podría interpretar este resultado, simplemente porque viven en esa especie de bucle melancólico del que siempre fracasa, esa especie de depresión. No ven las ayudas como ayudas, más bien como un estorbo. Puede que haya algo de esto, pero en cualquier caso estas personas no lo valoran todo negativamente, hay algunos cambios que los consideran positivos. ¿Cuáles son los cambios que sí consideran positivos de los que lleva a cabo el docente?. Lo primero y fundamental, que sea una persona cercana, que en lugar de despreciar al alumno que no va bien, lo aprecie y se acerque a él. En lugar de enfatizar los fracasos, que enfatice los pocos éxitos que tiene. Este es un factor que para ellos es muy relevante. Esta idea no es muy innovadora, estaba en los primeros trabajos de motivación de los años 30 del siglo pasado. Es decir, generar un sistema que lleve a todo el mundo a descubrir los avances y éxitos que consigue cada estudiante. Un sistema de evaluación que no sea una sentencia inapelable, sino un sistema de evaluación que permita tener información de logros y fallos y no solo una calificación como una sentencia final.

En este mismo sentido, los estudiantes que fallan aprecian cualquier cosa que haga el docente que no le haga hacer más el ridículo. Ya bastante avergonzados se sienten después de reprobar con frecuencia. Hacer cualquier cosa que lleve a señalarles en clase y que destaquen, aunque se haga con buena fe, es dañino. Enfatizar mucho eso de "Juanito, ¿te has enterado?". Esto es horroroso para ellos, porque ya tienen dañada la autoestima y hasta lo ánimos se interpretan mal. "Todos los demás ya saben que yo soy malo en esta asignatura. Si encima el profesor lo hace público y evidente, quiero desaparecer de la clase". Es decir, evitar cualquier tipo de comparación social o pública. Lo que quieren estos estudiantes es un entorno seguro y de apoyo social. Esta es la primera moraleja que os quería trasmitir hoy. Es decir, los estudiantes que más necesidades tienen de estar motivados para el aprendizaje, lo que te piden no es autonomía, lo que te piden no es autodeterminación, te piden cercanía, te piden que no les hagamos hacer el ridículo, te piden apoyo social. Necesitan un clima emocional, un 
clima afectivo de tranquilidad, de seguridad, de reconocimiento, pero que no falso ni impostado, sino auténtico. Para eso, una de las mejores soluciones es la evaluación continua y la retroalimentación continua del docente. Quieren que cuando se tenga éxito sea porque tienen éxito de verdad, no solo porque el docente quiera ayudar. En definitiva, que se genere un clima de apoyo y de cercanía donde pueda tener alguna probabilidad de éxito con lo que hago. Esto no es tan complicado, y a lo mejor estamos haciendo muchas intervenciones rebuscadas para los buenos estudiantes y olvidándonos de los esencial, para los que lo necesitan.

Todo lo que acabo de mencionar me hace sospechar que uno de los aspectos que es muy importante para la motivación intrínseca, es el apoyo social que tiene que ver con el clima emocional y el afectivo. No todo es la autonomía.

Ahora vamos a hablar de otro aspecto que no es puramente motivacional, pasamos de hoja. Vamos a hablar de Autorregulación, que es un proceso básico que determina la motivación. Algunos usan en su lugar el término de metacognición, otros hablan del término de procesos de conciencia, de reflexión, da igual. Vamos a usar aquí el término más cercano a los trabajos de motivación que es autorregulación.

La base de esta idea, es que en muchos casos una persona no tiene interés por realizar una tarea, por aprender, no porque no le guste la tarea o porque no tenga clara la relevancia de este aprendizaje sino porque no sabe cómo. El problema no es un problema motivacional, sino es un problema de estrategias. Es decir, "a mi la asignatura sí me gusta, pero con lo que yo tengo que hacer en esa asignatura y tal cómo lo da el profesor estoy tan despistado, que no se cómo seguir, de manera que la estoy dejando y ya no me gusta". En otros momentos de la psicología o de la filosofía a esto mismo se llamaba Voluntad. Uno de los ejemplos más sencillos de qué es la voluntad lo pone un psicólogo americano, uno de los padres de la psicología norteamericana que a lo mejor os suena, William James, que viene a decir que la voluntad se manifiesta todas las mañanas cuando nos despertamos. Son los procesos que llevamos a cabo desde que suena el despertador hasta que nos levantamos de la cama. Eso sí que es un acto de voluntad.
Todos recordamos el acto de voluntad de esta mañana. Los procesos de autorregulación son eso, actos de voluntad, que en el fondo son mensajes que nos decimos a nosotros mismos. No digáis en público lo que os habéis dicho esta mañana cuando ha sonado el despertador... Son mensajes que regulan nuestro comportamiento, que nos hacen tomar decisiones, que controlan lo que acabamos haciendo. Para los primeros trabajos de autorregulación, esos automensajes eran fundamentalmente cognitivos. Es aquello que gobierna nuestro comportamiento y que por lo tanto nos hace levantarnos por la mañana y que en términos generales acaba siendo una evaluación de beneficios-costos. Nos planteamos qué tenemos que hacer en ese día, descartamos las alternativas que más nos perjudican y nos quedamos con las que más nos benefician. Duele levantarse pero es mejor hacerlo, seguro que si te quedas en la cama se te va a complicar la vida. Por decirlo así, la mayoría de los modelos de autorregulación seguían una perspectiva cognitiva. Básicamente se trata de una serie de procesos de control consciente como la planificación. Es decir, todos los automensajes que nos damos sobre cómo tenemos que ordenar una actividad que tenemos que seguir: "cómo aprendo esta asignatura del master","qué pasos tengo que dar para poder terminar el trabajo que me han pedido". Lo que viene a decir también la teoría es que, en la medida en que seamos más concientes de cómo planificamos, podemos corregir nuestros malos estilos de organización y acabaremos automatizando los nuevos y buenos estilos. Todo es muy cognitivo, todo muy racional.

El siguiente proceso es el de supervisión, que llamáis aquí de monitoreo. Todos los procesos de automensajes, lo denomino así porque, nos representamos como si nos estuviésemos hablando a nosotros mismos, “...de hecho ahora que estoy de viaje estoy muy cansando de mi mismo. En las doce horas que mañana me tocan en el avión me acabo odiando, porque nada más que hago hablarme". Los mensajes de autosupervisión son aquellos mensajes que yo me doy, para ver si voy bien o voy mal. Si me está saliendo lo que quiero o no. Lo que dice la teoría también es que en la medida que yo tenga un sistema de supervisión más o menos conciente, mas o menos riguroso, mejor haré las tareas. Llegará un momento que 
lo tendré tan automatizado que superviso casi sin darme cuenta. Les pongo un ejemplo muy concreto. Cuando aprendemos a manejar un auto los procesos de planificación y supervisión los hacemos explícitos y conscientes pero luego, cuando ya somos expertos los procesos se vuelven subconscientes. Es lo que sucede cuando nos subimos al automóvil y no nos damos cuenta de que estamos manejando hasta que llegamos al lugar que deseamos. Esto que puede ser causa de problemas, muchas veces no genera ninguno. Esto es un ejemplo claro que los procesos se han automatizado tanto que, hemos conducido de forma subconsciente porque no ha habido ningún problema, porque si hubiese habido un problema el sistema hubiera levantado la alerta y el proceso se volvería conciente.

Al final, los últimos procesos de regulación cognitiva más importantes son los de evaluación. No es supervisión sino análisis, ver qué me ha salido bien, qué me ha salido mal. Si quiero aumentar mis destrezas evaluadoras lo que tengo que hacer es aumentar mi capacidad de autoevaluación. Tengo que hacer un análisis de lo que me ha ido bien, de lo que me ha ido mal y de cómo cambiar en el futuro. Si lo hago de forma conciente en un primer momento, lo puedo poco a poco ir automatizando para que en aquellas tareas en las que ya soy un experto, las evaluaciones las hago de forma automática, casi sin darme cuenta. Si soy experto en alguna tarea, pintar un cuadro por ejemplo, haces un análisis muy rápido de la calidad de tu trabajo porque ya está automatizado.

En este campo ocurre lo mismo que pasaba con la motivación intrínseca, de nuevo los conocimientos que estamos describiendo son de los años noventa, tienen ya veinte años. De manera que se han puesto en marcha muchos trabajos para ayudar a pensar, hay muchas intervenciones en estrategias de aprendizaje que son términos que quizá conocéis. En el fondo también tienen parecido de familia con la autorregulación. ¿Y cuáles son los resultados de las intervenciones para ayudar a pensar, para ayudar a autorregular? Los mismos que se obtenía en motivar para el aprendizaje. Cuando uno ayuda a pensar en contextos de laboratorio funciona, pero cuando la intervención se hace en contextos reales, no hay evidencias fuertes, pruebas reales que funcionan. Hay un artículo de Paris y Paris del 2004, que hace un estudio demoledor de si la autorregulación se puede enseñar y aprender explícitamente. Por lo general los resultados son pobres. Incluso cuando funciona, si vuelves al cabo de un tiempo, lo que aprendieron antes ya casi no lo usan. Aquellos que habían aprendido a autorregularse lo habían dejado, por costoso, porque no sabían hacerlo bien, por complejo, porque no es como manejar un auto, etc.

En paraleloalos desarrollos de autorregulación cognitiva, empezaron a surgir autores que hablaban de otro sistema de autorregulación. Más cercano a la autorregulación de los afectos y de las emociones. O más cercano a lo que algunos autores llaman volitivo, relacionado a la fuerza de voluntad. El control volitivo, como se suele usar este término, viene de la mano al auge -en la psicología- del poder de los afectos. Se empieza a considerar que lo que nos hace realmente inteligentes a los humanos no es nuestra capacidad operatoria, que parecía lo más excelso de nuestra inteligencia, las computadoras ya hace mucho tiempo que ganan al ajedrez a las personas. Calculan estratégicamente mejor que nosotros. Pero la mente humana supera a la maquina en otra cosa, podemos manejar nuestras emociones y las de otros y una máquina no. Hay una alteración psicológica del desarrollo que llama mucho la atención, que es el autismo. Este trastorno deja a la persona en un ciego emocional. Un breve ejemplo, el autismo de alto rendimiento, o Síndrome de Asperger, se caracteriza por ser personas con una gran capacidad operatoria, yo conocí algunos de ellos, que les tirabas palillos al suelo y los contaba exactamente en breves instantes. Esa misma persona cuando murió uno de los padres de la psicología de España, Ángel Riviere, que fue su terapeuta, me llamó en el entierro y me dijo: "Juan me pasa una cosa", le dije "qué bien!" pues era muy raro que le pasara algo, "se me están llenando los ojos de agua". Me pareció una frase tremenda, estaba en el entierro de su terapeuta y estaba sintiendo la emoción pero no era capaz de darle sentido pleno. Son también personas que no saben mentir.

Volvamos al asunto, para mucha psicología, la última frontera de la mente humana es la que nos permite mentir, chantajear, jugar con las emociones de los demás. De hecho, el lugar 
donde reside el control de las emociones, es donde la mente humana ha tenido su última fase de desarrollo neuronal, en la frente, en la corteza prefrontal. El hombre de Neandertal, el pariente más cercano al Homo Sapiens, no tenía tan desarrollada esa zona. El hombre de Cromagnon mucho más débil, podía jugar con las mentes, le mentía y pudo con él.

Aparece también, desde hace poco tiempo un término que no me gusta, pero que se ha hecho famoso que es el de inteligencia emocional. Prefiero el concepto de control volitivo, la mente tiene que regular y autorregular también las emociones y los afectos, que es lo más difícil y complicado. Entonces aparecen estudios que intentan descubrir que hay dentro de la caja negra del control volitivo. Lo que os presento aquí es una síntesis del trabajo hecho por Daniel Trías, Esther García y yo mismo hace pocos meses. Para nosotros la cajita negra del control volitivo tiene al menos las tres cajitas anteriores, la cuarta es donde tenemos dudas de donde colocarla. Hay dos autores por encima de nosotros en sabiduría y bien hacer, Corno y Kuhl. Kuhl fue el director de tesis de una profesora de aquí, Soledad Cordero y es realmente un genio en estas cosas. Khul habla que uno de esos componentes volitivos es el control de la motivación. Es tener presente cuáles son las metas que yo me propongo y saber cómo las voy alcanzando. Hacer un análisis de cómo va mi motivación. Para poder regular una actividad compleja, debo también tener presente nuestros deseos y propósitos y cómo se va consiguiendo.

La siguiente cajita tiene que ver con los mecanismos que usamos para concentrarnos, para relajarnos cuando la actividad se vuelve un poco estresante, las estrategias que usamos cuando no sabemos cómo progresar, cómo hacer para cumplir con tantas metas simultaneas, lo que Khul denomina como hipermotivación, que suele desembocar en una especie de bloqueo mental, o en el fenómeno de la mente en blanco. También aquí se encuentran los procesos relacionados con el control de impulsividad, una de las profesoras que están en nuestro proyecto de control volitivo decían a sus estudiantes "pará, pará", es decir, no te lances, tranquilo. También el control volitivo tiene que ver con las estrategias para controlar las emociones positivas y sobre todo las negativas. Cuando yo obtengo un resultado que me genera frustración o tristeza, es fundamental poder salir de esa situación, saber desconectarme de las emociones negativas y no quedarme centrado en cómo me baja la autoestima. También es conveniente mantener mis emociones positivas en un término medio, no sentirnos Gardel. Saber plantearnos retos que nos generen la sensación de "que vas bien". Desviar la atención cuando la situación sea de fracaso, saber salir de la frustración, etc., etc.

El modo de afrontamiento es la síntesis de los estilos que tienen las personas para usar las tres cajitas de arriba. En definitiva, todo esto es un breve resumen de lo que, ahora la literatura entiende como factores relevantes sobre el control volitivo.

¿Qué dicen los experimentos sobre los efectos de trabajar sobre la regulación volitiva o sobre la regulación emocional?. Las investigaciones actuales también demuestran que es más útil trabajar la faceta emocional que la cognitiva. Voy a ponerles dos ejemplos y con esto termino, lo juro. Hemos trabajado, mi compañera Arancha Ardura y yo mismo, con niños con sordera. Los hemos ordenado según su nivel de desarrollo lingüístico, y hemos contado con la colaboración de sus madres (porque sus padres nunca han venido). Les pedimos que les comentasen a sus hijos cómo podrían hacer una tarea difícil y hemos categorizado como les enseñan. Analizamos el tipo de expresiones que usaban para enseñar. No eran muchas madres las que participaron, porque la población era muy especial y las muestras grandes son muy difíciles de encontrar. El caso es que las madres que tienen niños sordos con mejor desarrollo lingüístico (niños más competentes) usan más cláusulas de regulación volitiva que cognitiva. Y las madres con hijos con peor desarrollo psicológico usan por igual la regulación volitiva y cognitiva. Bueno, esto solo es un dato correlacional, pero creemos que va en la línea que antes comentábamos.

Ahora os voy a enseñar datos de la tesis de Daniel Trías. Hemos hecho un pequeño experimento piloto con chicos que están aprendiendo matemáticas. Sobre el sistema que usan los docentes para enseñar hemos diseñado dos alternativas. Una en la que la 
docente brinda estrategias de control cognitivo: les habla como planificar, como evaluar y plantearse metas; y otra donde se hace hincapié en el control volitivo, cómo controlar la motivación, emociones, relajarse, etc. Esto, lo hemos hecho solo durante cuatro semanas en el nivel de secundaria. La variable dependiente, para ver la eficacia del modelo de enseñanza, era la cantidad de problemas matemáticos que resolvían bien antes de empezar la intervención y la cantidad de problemas bien solucionados luego de la intervención, se les ponía nueve problemas matemáticos antes de comenzar la intervención y nueve problemas matemáticos después. Después de cuatro semanas de clase, todos los estudiantes mejoraron -menos mal- si no cualquiera de las profesoras se suicidaba. En cualquier modalidad apareció un incremento de conocimientos después de la docencia. Pero la ganancia más llamativa era la que se producía en el grupo con intervención volitiva.
Los estudiantes con mejor rendimiento fueron aquellos que participaron de la estrategia volitiva.

Esto indicaría que al igual que en la motivación intrínseca, cuando se introducen aspectos emocionales, el rendimiento tiende a ser mejor. Probablemente el control volitivo no añade información muy nueva, lo que hace es abrir más la mente.

Con estos dos ejemplos he querido demostrar la importancia capital que tienen los efectos de los afectos en la motivación y el control consciente. No se si les habré convencido, me quedaría muy satisfecho si al menos me han entendido algo.

Muchas gracias a todos por ser tan amables y pacientes, espero ahora sus preguntas.

1 (N. de la Ed.). Conferencia dictada por el Prof. Dr. Juan Antonio Huertas el 12 de marzo de 2012 en el marco de las actividades de los programas de la Maestría en Psicología Educacional y el Postgrado de Especialización en Psicología Educacional (revisada por el autor). Invitado por el Departamento de Psicología del Desarrollo y Educación, de la Facultad de Psicología de la Universidad Católica del Uruguay.

El Prof. Dr. Juan Antonio Huertas, es Profesor Titular de Psicología Básica desde 1991. Actualmente es Vicerrector de Estudios de Grado de la Universidad Autónoma de Madrid, España. Conferencista invitado en innumerables Universidades. Académico y persona que busca respuestas desde la ciencia, ha dedicado años de estudio a la investigación y a la formación de generaciones de profesionales en Psicología, Psicopedagogía, Educación y muchas otras áreas. Autor de múltiples libros, capítulos de libros y más de 50 artículos en revistas especializadas. Una persona que enseña el camino del cuestionamiento, fomenta la inquietud por la búsqueda de respuestas y por y para ello, discurre sobre la Motivación.

Para citar este artículo:

Huertas, J. A. (2012). Los efectos de los afectos en la motivación y en la autorregulación.

Ciencias Psicológicas VI (1): 45-55. 